\title{
ASPECTS OF THE ENDOTHELIN SYSTEM IN COLORECTAL CANCER
}

\author{
Mohamed Refaat Mahdi',2, Raouf Fekry Bedeer', Abd-El Hakiem Zohry Gabr', \\ Huda Mohamed Eltahry', and Martin R. Berger ${ }^{{ }^{*}}$ \\ ${ }^{1}$ German Cancer Research Center (DKFZ), Toxicology and Chemotherapy Unit, Heidelberg, Germany, \\ ${ }^{2}$ Department of Human Anatomy and Embryology, Faculty of Medicine, Mansoura University, Egypt
}

Endothelin system members including endothelin-1, endothelin-2, endothelin-3, endothelin receptors, and endothelin converting enzyme are considered major regulating factors in cancer cell biology and cancer microenvironment. Endothelins are members of the matrix metalloproteinase superfamily of proteases, which are released from pre-proteins, bind to their receptors with differential affinity, and are degraded following cellular uptake. For their structural similarity, endothelin-2 and endothelin-3 can be regarded as natural competitors for the endothelin-1 receptors and as natural antagonists of endothelin-1. Endothelin-1 is regulated at several levels, primarily at the level of transcription. Remarkably, endothelin-1 is overexpressed in colorectal cancer, and elevated plasma levels were found in colorectal cancer patients. Endothelin receptor type A has an unequal distribution in the colon, as it is over-expressed in the proximal and distal segments of the colon. Compared with normal mucosal tissue, there is high expression of endothelin receptor type A and low expression of endothelin receptor type B in colorectal cancer at all Dukes stages. By binding to endothelin receptor type A, endothelin-1 leads to down-regulation of epithelial and increased expression of mesenchymal markers. Also, endothelin-1 acts as anti-apoptotic factor through multiple pathways like PI3K-dependent AKT activation or NF- $\kappa B$ signaling. Members of the endothelin system might be used as cancer biomarker and from a therapeutic point of view, targeting the endothelin axis is a promising aim. In effect, potential drugs may include endothelin converting enzyme inhibitors as well as selective and non-selective antagonists of endothelin receptor types $A$ and $B$.

Biomed Rev 2014; 25:1-13

Keywords: Endothelin 1-3, endothelin receptor, endothelin converting enzyme, cancer biomarker, endothelin receptor antagonist, endothelin converting enzyme inhibitor

Received 15 November 2014, revised 25 November 2014, accepted 5 December 2014

Correspondence to Prof. Martin R. Berger, German Cancer Research Center, Toxicology and Chemotherapy Unit,

Im Neuenheimer Feld 581, 69120 Heidelberg, Germany. Phone: +49-6221-423310, Fax: +49-6221-423313,

E-mail: m.berger@dkfz.de 


\section{INTRODUCTION}

The endothelin (EDN) system has a very important role in a variety of physiological and pathophysiologic processes including development, tissue differentiation, vasomotor tone, hormone production (1), pulmonary disease, cardiovascular disorders, renal diseases, wound healing, neurotransmission, and cancer biology (2). There are quite a few reviews describing the role of the EDN system in cancer, but there is limited information regarding its role in colorectal cancer. Because of our own interest, which was sparked by the growing evidence that the EDN system has bearing on colorectal cancer development, growth and metastasis, we found it appropriate to fill in this gap and review the EDN system for its role in this type of cancer.

\section{COMPONENTS OF THE ENDOTHELIN SYSTEM}

The EDN system consists of endothelin-1 (EDN-1), endothelin-2 (EDN-2), endothelin-3 (EDN-3), the G-protein-coupled receptors, endothelin receptor type A (EDNRA) and endothelin receptor type $\mathrm{B}$ (EDNRB), and endothelin converting enzyme (ECE) (3). Endothelins are characterized by a single alpha-helix and two disulfide bridges. There are three known isoforms, EDN-1 (or ET-1), EDN-2 (or ET-2) and END-3 (or ET-3) (4). A scheme of the EDN isoforms is given in Figure 1.
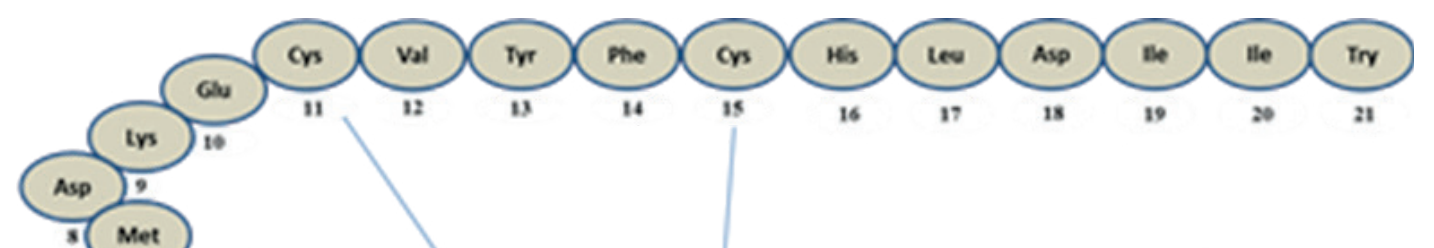

EDN-1
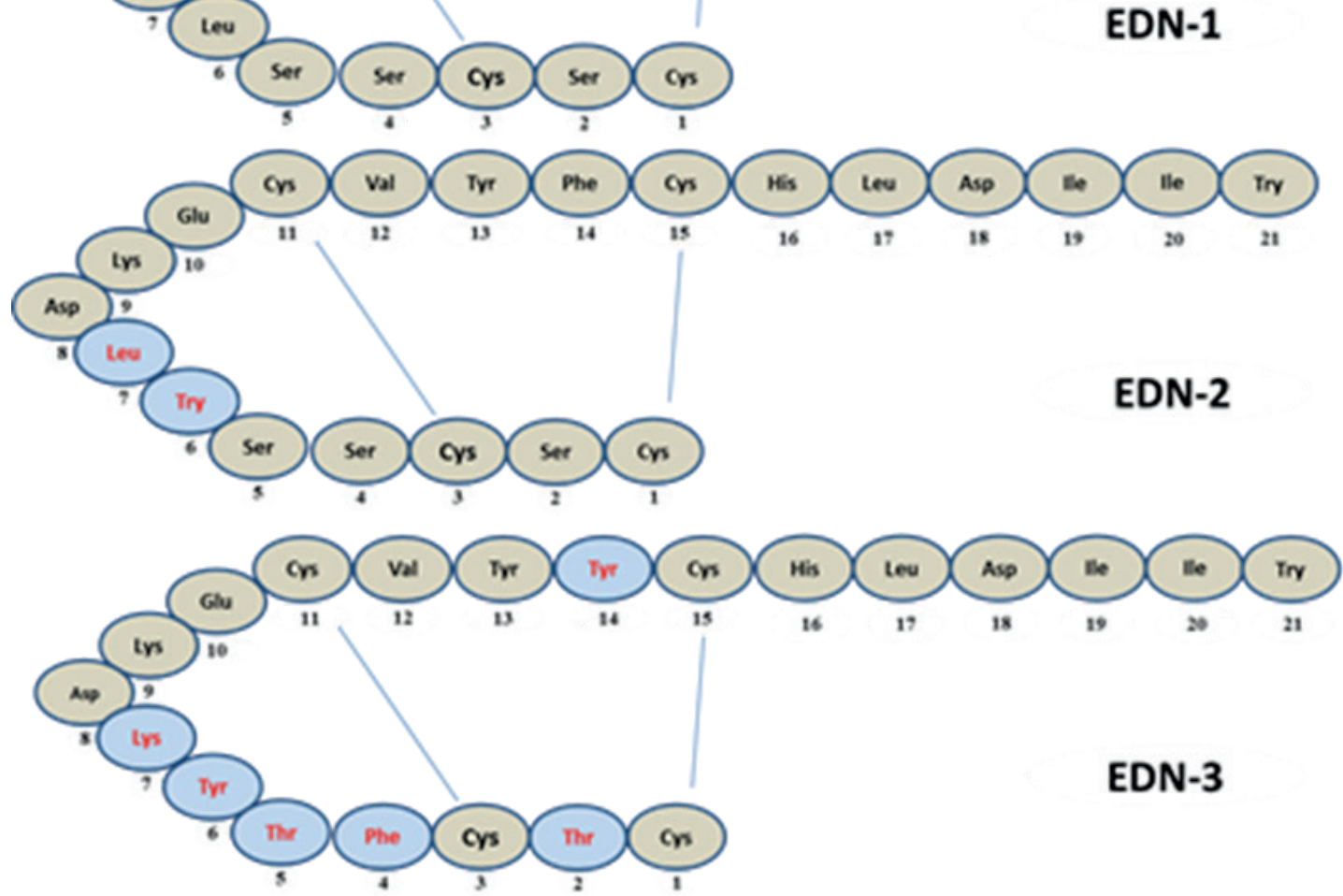

Figure 1. Scheme of the secondary structure and the amino acid sequence of endothelin-1 (EDN-1), endothelin-2 (EDN2), and endothelin-3 (EDN-3). Amino acids are symbolized by circles. Sulfur double bonds between cysteine residues are indicated by a straight line. Differences in the amino acid composition of EDN-2 and EDN-3 versus EDN-1 are indicated by blue circles and red amino acid abbreviations. The numbers below the circles denote the amino acid sequence from the amino to the carboxyl terminus (The sequences correspond to the following datasets: EDN-1: UniProtKB/Swiss-Prot: P05305.1; EDN-2: GenBank: EAX07175.1; EDN-3: NP 996917.1) 


\section{Endothelin-1}

Endothelin-1 is a member of the matrix metalloproteinase superfamily of proteases (5). The primary transcript of EDN1 is termed prepro-EDN-1, the gene of which is located on chromosome 6 , there spanning $6.8 \mathrm{~kb}$ and containing five exons (6). This protein is then transformed to big-EDN-1, and further to the active 21-aa EDN-1 via endothelin converting enzyme (ECE). A corresponding scheme is shown in Figure 2.

Endothelin-1 is synthesized, expressed and secreted not only from endothelial cells but also from macrophages, fibroblasts, vascular endothelial cells, smooth muscle cells, neurons, and epithelial cells of the airways and oral cavity (7). Degradation of EDN-1 is done by EDN-1 receptor type B (EDNRB) mediated cellular uptake followed by lysosomal degradation (8), or through degradation by the extracellular neutral endopeptidase 24.11 (9). Endothelin-1 is well known as a potent vasoconstrictor (10) and has a role in tumor initiation and progression via autocrine and paracrine mechanisms (6). It acts through different signaling pathways and is involved in normal cell functions as well as in those contributing to cancer development and progression, including cell proliferation, apoptosis, epithelial mesenchymal transition, invasion, metastasis, and tumor angiogenesis. Based on these properties, EDN-1 and its signaling axis are considered very attractive targets for cancer therapy (11).

Endothelin gene (chromosome 6)
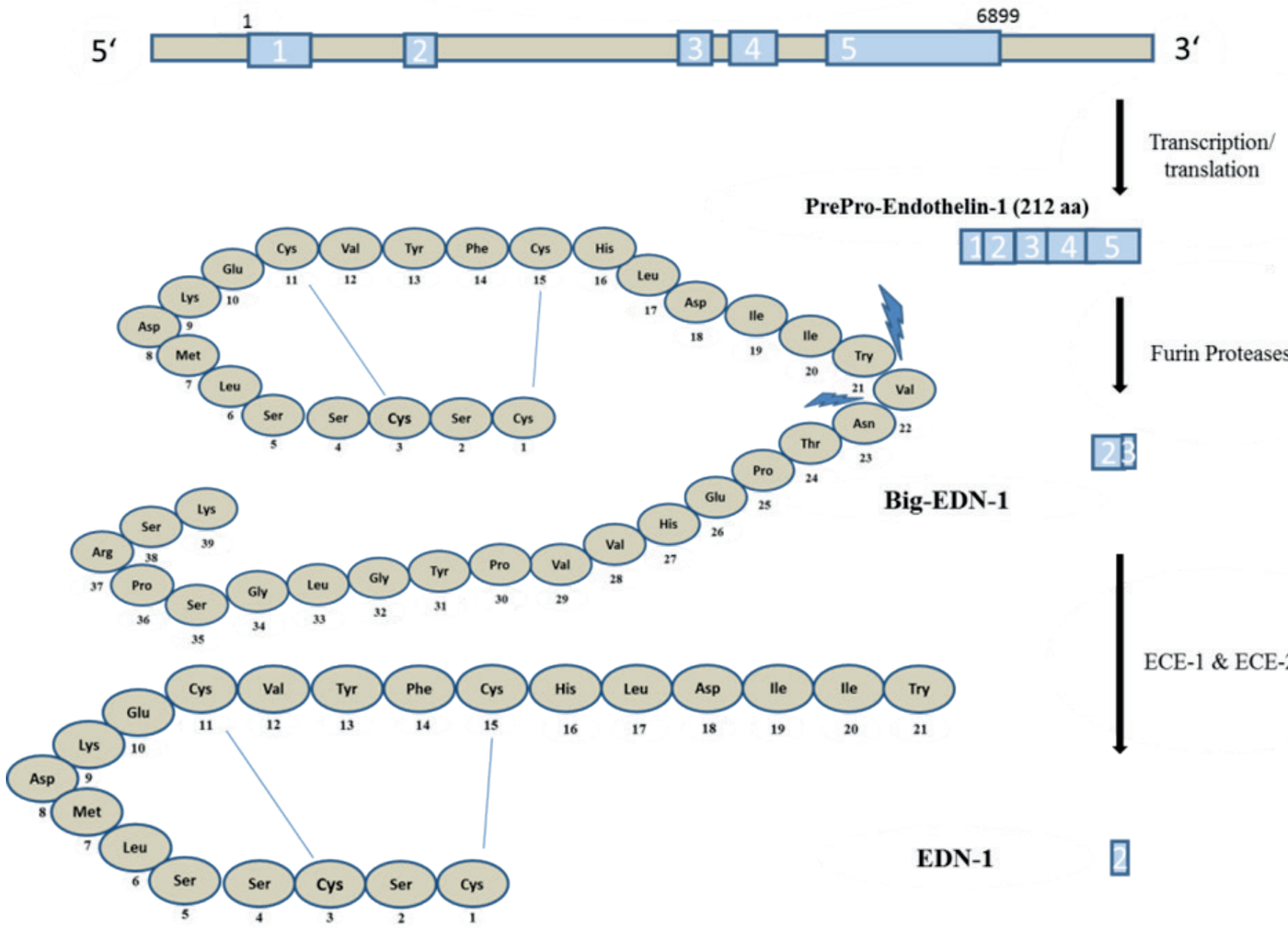

ECE-1 \& ECE-2

Figure 2. Scheme of endothelin-1 synthesis: The endothelin gene is located on chromosome 6 and comprises five exons (blue boxes) and six introns. Following transcription, the 216 amino acids containing prepro-endothelin-1 is expressed, which then is cleaved by furin proteases to become big endothelin (big-EDN-1) and finally by endothelin converting enzymes (ECE-1 and $E C E-2)$ to become active endothelin 1 (EDN-1). 


\section{Endothelin-2 and endothelin-3}

There is less research published on the roles of EDN-2 and EDN-3 in cancer as compared to EDN-1. The EDN-2 gene is present on chromosome 1, while the EDN-3 gene is located on chromosome 20 (12). In comparison to EDN-1, which is distributed in all rat organs examined (13), EDN-2 expression is more restricted to certain human and rat organs, including the intestines (14). Interestingly, EDN-2 has an unequal distribution in the colon; it is immunolocalized at the middle and upper parts of a crypt in the proximal colon and in the base of crypts in the distal colon (15). Endothelin-2 is known as a hypoxia inducible and antihypoxic factor. In human breast cancer, EDN-2 is reported to be a survival factor against hypoxia, whereas in a rat model of colonic tumorigenesis, EDN-2 and EDN-3 expression is lost several weeks before the onset of colon cancer. However, if these rats were treated with 5-aza-2'-deoxycytidine (5-aza-dC), their colonic mucosa showed re-expression of both, EDN-2 and EDN-3, but with a preference for EDN-2, the expression of which was greater than that of EDN-3. Moreover, forced re-expression of EDN-2 and EDN-3 in human colon cancer cells in vitro led to inhibition of invasion and migration. Thus, in human and rat colon cancer cell lines as well as in human primary colon cancers, there is down-regulation and hyper-methylation of the EDN-2 and EDN-3 genes. For their structural similarity, EDN-2 and EDN-3 can be considered as natural competitors for the EDN-1 receptor and as natural antagonists of EDN-1, and in line with this notion they have anticancer effects (3). A short summary is shown in Table 1 regarding the increased expression of members of the EDN system in colon cancer cell lines SW480, SW620 and HT29 following exposure to the demethylating agent 5-aza-2'-deoxycytidine (unpublished own results).

\section{Endothelin receptors type $A$ and $B$}

Endothelin receptors type A and B (EDNRA and EDNRB) are members of the family $A$ of $G$ protein-coupled receptors (GPCRs, the 'druggable' class). EDNRA affinity to EDN1 and EDN-2 is twofold higher than its affinity to EDN-3, while the affinity of EDNRB is equal to EDN-1, EDN-2 and EDN-3 (6). The genes of EDNRA and EDNRB are located on chromosomes 4 and 13 (16). There is a heterogeneous distribution of the endothelin receptors at cellular, tissue and organ levels. EDNRA and EDNRB may have the same or the opposite effect, but in general most of the EDN-1 effect is mediated by EDNRA (7). EDNRA has an unequal distribution in the colon, as it is over-expressed in the proximal and distal segments of the colon (17). Endothelin receptors type B is considered as the predominant receptor in normal colon, but in colon cancer it is down-regulated in cancer associated blood vessels, fibroblasts and epithelial cells (17). Moreover, epigenetic alteration of EDNRB expression by aberrant methylation has an important role in the pathogenesis of hepatocellular carcinoma (18), and in gastric cancer (19).

Activation of EDNRB by EDN-1 in normal and some tumor cells leads to the induction of EDN-1 clearance, which then stimulates cellular apoptosis, thus having an anticancer effect (20). However in other tumor types EDNRB enhances cancer progression and was found to be overexpressed, such as in melanoma (21) and oligodendroglioma (22). In line with this, BQ788, a specific EDNRB antagonist, can inhibit the growth of human melanoma tumors cells in nude mice (21).

There are three types of EDNRA and EDNRB expression in cancer in general: the first type expresses predominantly EDNRA, as found for colon, pancreatic, gastric, renal and breast, nasopharyngeal, thyroid, and prostate cancers; the second type expresses predominantly EDNRB, as in melanoma

Table 1. Expression of members of the endothelin system in colorectal cancer cell lines

\begin{tabular}{|l|c|c|}
\hline $\begin{array}{l}\text { Endothelin system } \\
\text { member }\end{array}$ & $\begin{array}{l}\text { Expression in } \\
\text { control cells }\end{array}$ & $\begin{array}{l}\text { Expression in 5-aza-2'-deoxycytidine treated colorectal } \\
\text { cancer cells (SW480, SW620, and HT-29) }\end{array}$ \\
\hline EDN-1 & + & ++ \\
\hline EDN-2 & - & + \\
\hline EDN-3 & - & + \\
\hline ECE-1 & + & + \\
\hline ECE-2 & - & - \\
\hline EDNRA & + & - \\
\hline EDNRB & - & + \\
\hline
\end{tabular}

- no detectable expression; + detectable expression; ++ strong expression 
and brain tumors (glioblastoma and astrocytoma); the third type expresses both, EDNRA and EDNRB, as in oral, lung, bladder, vulvar and ovarian cancers (23).

\section{Endothelin converting enzyme}

Endothelin converting enzyme (ECE) is a membrane bound enzyme, which is responsible for EDN-1 production and can control the level of EDN-1. There are two types of endothelin converting enzyme, ECE-1 (24) and ECE-2 (25). Both of them are membrane-bound, zinc-binding metalloproteases. Endothelin converting enzyme-1 is present mainly at the cell surface, while ECE-2 exists predominantly in the cytosol. Also, ECE-1 has a wide tissue distribution with highest expression in liver, while ECE-2 has a neuroendocrine distribution. Both of them can act on big-EDN-1, big-EDN-2 and big-EDN-3, but with higher affinity to big EDN-1 (7).

The ECE-1 gene is located on chromosome 1 and has the four isoforms ECE-1a, ECE-1b, ECE-1c and ECE-1d (26). These isoforms have different subcellular localization and effects due to differences in their N-terminal cytoplasmic regions (27).

\section{VARIATION OF ENDOTHELIN AXIS COMPONENTS' EXPRESSION IN COLORECTAL CANCER}

Endothelin-1 is overexpressed in many gastrointestinal tumors including colorectal and gastric cancers (28). Increased expression of EDN-1 was demonstrated by immunohistochemistry and immune-electron-microscopy in colorectal cancer primaries and liver metastases, as well as in endothelial and stromal cells $(29,30)$. Over-expression of prepro-EDN-1, ECE-1, and EDNRA and EDNRB was found in human colon adenomas and adenocarcinomas as compared to normal colon. Also, prepro-EDN-1 and ECE-1 were overproduced from carcinoma and stromal vessel cells, thus they may be considered as the source of local EDN-1. There are large amounts of EDNRA in stromal myofibroblasts of cancer tissue, and large amounts of EDNRB in endothelial cells and myofibroblasts $(2,31)$.

Elevated plasma levels of EDN-1 were found in colorectal cancer patients with or without liver metastasis (32). EDN-1 is over-expressed in endothelial cells within liver metastasis in comparison to surrounding vessels in patients with colorectal cancer, thus EDN-1 can modulate metastatic liver blood vessels (30). In fact, in $80 \%$ of primary human colon cancers there is EDN-1 overexpression (33). In normal mucosa and early stage colon cancer cells there is still normal expression of EDN-1, but overexpression develops during later stages of colon cancer (15). The role of EDN-1 in cancer may be due to over-expression of EDN-1 or overexpression of its receptors, or their signaling pathways. These changes in EDN-1 axis are due to genetic and epigenetic changes as DNA methylation and histone modification (6). Similarly, in human and rat colon cancers there are very low to undetectable expression levels of EDN-2 and EDN-3, as a result of epigenetic silencing (3).

Compared with normal mucosal tissue, there is high expression of EDNRA and low expression of EDNRB in colorectal cancer $(17,34)$ at all Dukes stages $(35)$. This was found also in colorectal cancer cells and cancer associated cells (fibroblasts and endothelial cells) in comparison with normal tissue (17). In line with these findings in colorectal cancer, there is similar expression in other gastrointestinal cancers such as gastric cancer $(19,36)$ and hepatocellular cancer (18). Regarding the colorectal cancer cell lines LIM1215, HT29, SKCO1, SKCO17 and LoVo, there is high expression of EDNRA and low expression of EDNRB in comparison to normal colon (35).

\section{REGULATORY FACTORS OF ENDOTHELIN-1}

The secretion of EDN-1 is stimulated by mechanical factors (vascular shear stress), metabolic factors (hypoxia), endocrine factors (thrombin, insulin, aldosterone, adrenaline, leptin and cortisol) and paracrine factors (transforming growth factor beta, angiotensin II and inflammatory mediators) (7). Also, EDN-1 production can be inhibited by nitric oxide, prostacyclin and atrial natriuretic peptide (1). Endothelin-1 is regulated at several levels, primarily at the level of transcription by more than 20 different stimuli, with each acting on specific tissues and cells and having its own regulatory factors. Endothelin-1 is controlled by a TATA box-containing promoter. Activator protein-1 (AP-1) is present within the proximal promoter and contains binding sites for FOS and JUN transcription factors. Also, there are binding sites for transforming growth factor- $\beta$ (TGF- $\beta$ )-activated SMAD transcription factors, GATA family transcription factors and hypoxia-inducible factor 1 (HIF1) in the proximal EDN-1 promoter (see Fig. 3).

Meanwhile, there are other binding sites in the distal EDN1 promoter such as a hormone-responsive element, a nuclear factor- $\mathrm{KB}(\mathrm{NF}-\mathrm{\kappa B})$, an E-box motif and two nuclear factors of activated $\mathrm{T}$ cell binding sites. EDN-1 is regulated also at the post transcriptional level, as the $3^{\prime}$-untranslated region (3' UTR) of EDN-1 contains AUUUA motifs, which bind to certain proteins and regulate RNA degradation or stabilization. Also, EDN-1 mRNA can be regulated by microRNA species (miR-155 or miR-199) (37). 


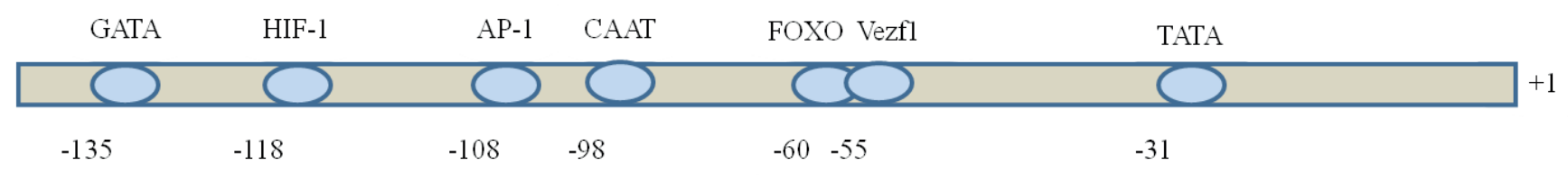

Figure 3. Scheme of endothelin-1 promotor regulation: Core motives (GATA; GATA transcription factors), HIF-1 (hypoxia inducible factor-1); AP-1 (activator protein-1); CAAT (consensus sequence signaling the RNA transcription factor binding site); FOXO (forkhead box); Vezfl (vascular endothelial zinc finger binding protein f1); TATA [consensus sequence signaling the binding site of either general transcription factors or histones) are indicated by circles. Nucleotide positions are numbered relative to the primary transcriptional start site and correspond to the human EDN1 gene (NCBI accession no. NC_000006).

\section{ENDOTHELIN-1 ROLE IN CANCER CELL BIOLOGY}

Endothelin-1 activates several intracellular pathways including phospholipases $\mathrm{C}$ and $\mathrm{D}$, phospholipase $\mathrm{A} 2$, adenylate cyclase and guanylate cyclase. The former two enzymes stimulate protein kinase $\mathrm{C}$ (PKC) and phosphoinositide 3-kinase (PI3K), and this leads to stimulation of the mitogen activating protein kinase (MAPK) pathway (28). In colorectal cancer patients there is up-regulation of EDNRA and down-regulation of EDNRB, which has bearing on the AKT pathway. This pathway is characterized by up-regulation of AKT, hypoxiainducible factor 1-alpha subunit (HIF1 $\alpha$ ) and VEGF that lead to stimulation of angiogenesis and improved cell survival. Also, there is an increase in the expression of glycogen synthase kinase 3 beta (GSK3B), snail homologue 1(SNAI1), catenin (cadherin-associated protein) beta 1 (CTNNB1, $\beta$-catenin), and cyclin D1. Moreover, there is over-expression of transcription factors, which are responsible for mesenchymal cell phenotypes like goosecoidhomeobox (GSC), twist homologue 1 (TWIST), lymphoid enhancer-binding factor 1 (LEF1), E2A immunoglobulin enhancer binding factors E12/E47 (TCF3), forkhead box $\mathrm{C} 1$ (FOXC1) and FOXC2. Over-expression of SNAI1, TCF3, TWIST, FOXC1, FOXC2 and GSC lead to down-regulation of E-cadherin, and this down-regulation in primary colon cancer was described to be associated with lymph node and liver metastasis (38). However, others reported no difference in E-cadherin expression in colon carcinomas (39).

In human colon cancer, inactivating mutations of the APC gene or activating mutations of the $\beta$-catenin gene lead to $\beta$-catenin/TCF4 complex formation on the EDN-1 promotor, and this complex finally stimulates transcription of EDN-1 and subsequent over-expression (32). There is a positive feedback loop between EDN-1 and $\beta$-catenin via the PI3K pathway (40). In normal cells, free $\beta$-catenin is degraded after phosphorylation by the APC/Axin/GSK3b complex (41). In $85 \%$ of sporadic colon cancer patients, there is mutational inactivation of the APC gene, which leads to aberrant $\beta$-catenin pathway activation (42). In a minority of sporadic colon cancers cases, there is a mutation in the residues of the $\beta$-catenin gene, which leads also to $\beta$-catenin pathway activation because $\beta$-catenin cannot be targeted for proteasomal degradation (43). As a result, Wnt signaling stabilizes free cytoplasmic $\beta$-catenin, then stable $\beta$-catenin can enter into the nucleus and form a complex with the lymphoid enhancer factor/T-cell factor (LEF/TCF) family of DNA binding proteins, and start its tumorigenic gene transcription (44).

\section{Cell proliferation}

Endothelin-1 acts as autocrine promoter of cell proliferation via EDNRA (45). In addition, mitogenic effects of EDN-1 in cell proliferation can be promoted by the action of other growth factors like EGF, basic fibroblast growth factor, insulin, insulin-like growth factors 1 and 2, platelet-derived growth factor, TGF $\beta$ and IL-6 (6). As established for colon cancer cells, activation of EGFR occurs through the $G$ protein coupled receptors (GPCR), their $\beta$-arrestin regulators and the c-Src pathway (46).

\section{Cell survival}

Endothelin-1 acts as anti-apoptotic factor through multiple pathways like PI3K-dependent AKT activation or NF-KB signaling (47). Likewise, it acts as anti-apoptotic and survival factor against FAS Ligand (FASL)-induced apoptosis in colon 
carcinoma (48). MYC is one of the genes, which is targeted by the $\beta$-catenin pathway. EDN-1 is responsible for suppression of MYC-induced and FasL-induced apoptosis. Also, EDN1 acts as a survival factor against apoptosis of colon cancer cells as a result of its inhibiting the $\beta$-catenin pathway, and this may be due to AKT activation (49). Endothelin-1 receptor antagonists promote the effect of conventional chemotherapy in many cancer cell lines including colon cancer by induction of cancer cell apoptosis (50).

\section{Migration and invasion}

Cancer cells secrete proteases in order to lose polarity and cell to cell junctions, and acquire mesenchymal character to invade the extracellular matrix (ECM) and subsequently form metastases (51). Endothelin-1 modulates the gene transcription, secretion and activation of the resultant proenzymes of two families of metastasis related proteinases, the urokinase-type plasminogen activator (uPA) system and the matrix metalloproteinases (MMP). Also, EDN-1 contributes to activation of p125 focal adhesion kinase (FAK), paxillin and RHO, which are involved in tumor cell motility and invasion (6). Epithelial to mesenchymal transition (EMT) is part of the initial stage of any metastatic process within cancer progression, in which cancer cells will lose many of their epithelial characters, like cell to cell adhesion, polarity and lack of motility, and transfer to become more like mesenchymal cells (38). By binding to EDNRA, EDN-1 leads to down-regulation of epithelial markers as E-cadherin and increased expression of mesenchymal markers as $\beta$-catenin, Snail, N-cadherin and vimentin (52).

The phosphatase and tensin homolog (PTEN) is considered a tumor suppressor gene, which inhibits the PI3K/AKT pathway as well as the EDN axis (53). In human colon cancer cells, loss of PTEN can induce EMT (54). It is found significantly downregulated in patients with colorectal cancer metastasis, especially in comparison with non-metastatic disease (38).

\section{Metastasis}

Metastasis is a complex process that needs interaction between cancer cells with the host microenvironment, and it involves tumor cell invasion, epithelial mesenchymal transition (EMT), shedding from the primary tumor, intravasation, arrest within blood vessels, extravasation and colonization of a preferential organ. EDN-1 starts autocrine and paracrine signaling cascades in tumor, immune and stromal cells, at both primary and distant sites, that lead to cancer invasion and metastasis (32).

\section{ENDOTHELIN-1 AND CANCER STROMA}

Endothelin-1 has an enhancing effect on cancer cell proliferation, survival, invasion and migration; also it has an effect on cancer stroma cells such as fibroblasts (proliferation, migration, contraction, ECM remodeling), macrophages (chemo-attraction, ECM remodeling) and endothelial cells (proliferation, angiogenesis) (5). Endothelin-1, which is produced by stromal and tumor cells, acts through different signaling pathways by EDNRA activation (AKT, MAPK, PKC, EGFR), and leads to stimulation of angiogenesis (by HIF-1a, VEGF, Cox-1/-2, PGE2), anti-apoptotic effects (AKT, NFKB), cell migration and adhesion (integrins, ILK, FAK, cadherins / catenins, connexins), increased invasion and expression of MMP and uPA (55). Endothelin-1 can stimulate fibroblast growth more by interacting with EDNRA, migration more by EDNRB, and fibroblast contraction by both of them. Also, it can stimulate the secretion of tissue inhibitor of MMP1 (TIMP-1), matrix metalloproteinase 2 (MMP-2), connective tissue growth factor (CTGF), and collagen XI, but has no effect on matrix metalloproteinase 3 (MMP-3). The increases in TIMP-1 and MMP-2 can be blocked by an EDNRA blocker more than an EDNRB blocker (56). Fibroblast cells isolated from normal tissue adjacent to colon cancer expressed EDNRA and EDNRB (28). In vitro, EDN-1 can stimulate growth, migration, contraction and the production of ECM-modifying proteins of fibroblasts, which were isolated from normal tissues adjacent to colon cancers (56). Thus, EDN-1 stimulates a stroma, which is supportive for tumor growth and progression, through its effect on tumor cells, macrophages and fibroblasts (6). Endothelin-1 stimulates endothelial cell migration and proliferation by EDNRB (57). Endothelin-1 receptor type B is over-expressed in endothelial cells and myofibroblasts of and around colorectal cancer vessels in comparison with normal colon mucosa. The EDN system affects tumor vasculature through interaction between myofibroblasts with endothelial cells and EDNRB induction (31).

\section{ENDOTHELIN-1 AND STEM CELLS}

There is interaction between cancer cells and mesenchymal stem cells (MSC) in colon cancer. Following subcutaneous injection of human colorectal cancer cells and MSC into immune-deficient mice, it was found that MSC can increase the growth rate of tumor cells and their related angiogenesis in comparison to the effect of carcinoma-associated fibroblasts or normal colonic fibroblasts. Also, MSC stimulate secretion of EDN-1 from cancer cells via interleukin-6 (IL-6), which 
in turn acts through Akt and ERK pathways of endothelial cells to stimulate recruitment of endothelial cells and tumor angiogenesis. This pathway can be blocked in MSC by siRNA, or in cancer cells through EDN-1 inhibition or knockdown, or in endothelial cells through inhibition of ERK and Akt (58).

The CD133 antigen is used as marker for cancer stem cells in colon cancer. These CD133 positive cancer stem cells show over-expression of EDN-1 and nuclear receptor subfamily 4, group A, member 2 (NR4A2) transcripts, and there is a relation between the expression of CD133, EDN-1 and NR4A2, as shown by siRNA knockdown of CD133 expression in CaCo-2 colorectal cancer cells, which caused a significant reduction in the expression of EDN-1 and NR4A2 (59).

\section{ENDOTHELIN SYSTEM MEMBERS AS BIOMARKERS IN CANCER}

In patients with colorectal cancer, there are high plasma levels of Big-EDN-1, and these levels are significantly higher in patients with liver metastasis, thus suggesting that Big-EDN-1 plasma levels can be used as a marker of colorectal cancer presence and disease progression (29). Preoperative plasma levels of big-EDN-1 can be used as a prognostic marker for overall survival in patients with colorectal cancer, and can be used as a parameter among others for adjuvant therapy (32). In contrast, other publications indicate that plasma levels of bigEDN-1 have no prognostic value in primary colorectal cancer patients (60). In line with this, elevated levels of serum EDN-1 had no prognostic value in colorectal cancer patients (61). Also, in colorectal cancer patients increased EDNRA was associated with increased tumor grade and reduced patient survival (34). There was loss of EDN-2 and EDN-3 in rat colon mucosa several weeks before the onset of colon cancer, favoring the notion that they can be used as early biomarker of cancer colon (3). Moreover, EDN system members help as prognostic factors in other cancers. EDN-1 expression in bladder cancer tissue is considered as a highly prognostic factor for patient survival, while plasma levels of big-EDN-1 can be an early diagnostic factor in patients with invasive breast cancer (62).

\section{Endothelin receptor antagonists in colorectal cancer}

From a clinical point of view, targeting the EDN axis is a promising aim in cancer therapy; which includes endothelin converting enzyme inhibitors as well as selective and nonselective antagonists of EDNRA and EDNRB. A selection of some of these agents is shown in Table 2.

Endothelin-1 receptor antagonists have a promising future in cancer therapy, especially with the invention of two oral EDNRA antagonists (ABT-627; atrasentan and ZD4054; zibotentan) (5). EDNRA antagonists are used in clinical trials of many types of cancer. For example, there is growing interest in using EDN receptor antagonists for prostatic cancer therapy (63). So far, however, there are only few trials in colorectal cancer patients. EDNRA selective antagonists (such as atrasentan and zibotentan) or dual EDNRA and EDNRB antagonists (such as macitentan) have inhibited colon cancer growth and induced apoptosis in vivo and in vitro, especially when combined with conventional chemotherapy (6). The human colorectal cancer cell lines LIM1215 and HT29 express

Table 2. Selected antagonists of the endothelin system

\begin{tabular}{|l|l|l|}
\hline Antagonist & Type & Company \\
\hline Atrasentan (ABT-627/A-147627) & EDNRA antagonist & Abott \\
\hline Darusentan (LU-135252) & EDNRA antagonist & Abott \\
\hline Zibotentan or ZD4054 & EDNRA antagonist & Astra Zeneca \\
\hline BQ-788 & EDNRB antagonist & Bachem \\
\hline BQ123 & EDNRA antagonist & Bachem \\
\hline Ambrisentan (LU208075/BSF-208075) & EDNRA antagonist & Myogen \\
\hline Bosentan (RO 47-0203) & EDNRA \& EDNRB antagonist & Actelion \\
\hline Phosphoramidon & Endothelin converting enzyme inhibitor & Cayman Chemicals \\
\hline
\end{tabular}


EDN-1, EDNRA and EDNRB. Addition of exogenous EDN-1 increased their cell number in a dose dependent manner, and these increases in cell number were inhibited by EDNRA antagonists BQ123 and BQ610, but not the EDNRB antagonist BQ788 (64). Specifically, the EDNRA antagonist BQ123 inhibited colorectal cancer cell proliferation in vitro. This was due to the fact that EDN-1 increased the proliferation of colorectal cancer cell lines (HT29, LIM1215 and SW620) by stimulation of DNA replication via EDNRA, and the effect was mediated via pertussis toxin-sensitive $\mathrm{G}$ proteins, phosphoinositide 3-kinase (PI3K), protein kinase $\mathrm{C}$ (PKC) and transactivation of the epidermal growth factor (EGF) receptor (65).

In colorectal cancer cell lines and associated fibroblasts isolated from patient tissues, cellular proliferation is inhibited by the EDNRA antagonist zibotentan; but migration is inhibited by the EDNRB antagonist BQ788 more than by the EDNRA antagonist, while contraction is inhibited by the combined use of EDNRA and EDNRB antagonists. Recently, zibotentan has been recommended for use as adjuvant therapy in colorectal cancer patients (28).

In line with this, the dual EDNRA and EDNRB antagonist bosentan incompletely inhibited tumor progression in an experimental rat model of colon carcinoma induction; it led to less densely packed tumor cells with less collagen matrix around tumor nodules (31).

In a rodent model of colorectal cancer, intraportal injection of BQ123, the EDNRA antagonist, inhibited micro-metastasis of cancer, especially if injected at the time when cancer cells were injected and not after that, because BQ123 can inhibit the effect of EDN1/EDNRA during cancer cell implantation and micro-metastasis formation (33).

Endothelin-1 inhibits FASL induced apoptosis in colorectal cancer, but bosentan, a dual EDNRA and EDNRB receptor antagonist, increases FASL induced apoptosis in human (HT29 and SW480) and rat (PROb and REGb) colon cancer cell lines. This inhibition is mediated by protein kinase $\mathrm{C}$ (PKC). Thus, EDN-1 acts as an anti-apoptotic factor not just as a direct proliferative agent. Bosentan usage in peritoneal tumors derived from a syngeneic rat colonic adenocarcinoma cell line led to a decreased death rate and a lower tumor grade in comparison with untreated rats, but it did not control tumor progression $(48,50,66)$.

In SW480 colorectal cancer cells, over-expression of EDNRA by an EDNRA expression vector led to increased cell invasion, cell survival against cisplatin, and matrix metalloproteinase (MMP)-2 expression, which was stimulated by exogenous ET-1, and inhibited by BQ123 and the phosphatidylinositol 3-kinase (PI3K) inhibitor LY294002. In line with this, knockdown of EDNRA had the opposite effect. EDNRA over-expression stimulated colon cancer liver metastases in a mouse model, and its knockdown produced the opposite effect (67).

EDN-1 is over-expressed in cytoplasm, stroma and blood vessels of human colon cancer, whereas in normal mucosa cells, EDN-1 expression is limited to apical layers of the epithelium, vascular endothelial cells and surrounding stroma. The plasma level of EDN-1 was found over-expressed in colorectal cancer patients, both with primary tumor and with metastases, and in a rat model of colorectal cancer. Moreover, intraportal injection of the selective EDNRA antagonist BQ123 reduced the weight of colorectal metastatic lesions inside the liver (33).

In a phase 1 clinical trial, the EDNRA antagonist atrasentan was used in 31 patients with prostate, colorectal, breast, lung, and renal cell carcinoma. There was some pains relieve and reduction in some tumor markers, but no radiological response or significant clinical benefit was detected (68).

Although the receptors EDNRA and EDNRB are similarly distributed in arteries supplying colorectal cancer and normal colon in the same colorectal cancer patients, the EDNRB antagonist BQ788 reduced the contractile response produced by EDN1 in arteries supplying colorectal tumor, but not that of arteries supplying normal colon, meanwhile, the EDNRA antagonist BQ123 reduced both types of arteries equally. It was deduced that arteries of colorectal cancer are more susceptible to EDN-1 due to EDNRB enhanced activity (69).

In colorectal cancer tissues from 42 human patient samples, there was hyper-methylation of the EDNRB promoter and this epigenetic silencing was associated with lower levels of EDNRB mRNA. This may indicate that EDNRB is a tumor suppressor gene, which is down-regulated by promoter hyper-methylation (70). There is growing interest in using endothelin receptor antagonists as adjuvant therapy, after failure of monotherapy. For example, there is an ongoing phase II clinical trial in patients with metastatic colorectal cancer with ZD4054 in combination with irinotecan, fluorouracil and folinicacid (FOLFIRI) after failure of oxaliplatin containing chemotherapy (71).

\section{ENDOTHELIN SYSTEM AND NON-CANCEROUS DISEASES}

The EDN system is linked with many pathological conditions such as cardiac and vascular diseases (congestive cardiac failure, coronary artery diseases, essential hypertension, 
atherosclerosis, Raynauds disease, and preeclampsia), renal diseases (acute renal injury, chronic renal failure, and renal remodeling), central nervous system disease (cerebrovascular disease), pulmonary diseases (asthma, cryptogenic fibrosing alveolitis, and pulmonary hypertension), and developmental disease (Hirschsprung's disease) (2).

Animals with knockout of ECE1, or deficient in the EDN-1/EDNRA and EDN-3/EDNRB pathways have similar phenotype, they are deficient in epidermal melanocytes, and therefore have white-spotted hair and skin color, but a normal eye color. Also, their distal colon (from sigmoid colon to the rectum) is narrowed and obstructed due to the absence of myenteric ganglia, with dilatation of the proximal colon, intestinal dysfunction, and premature death (72). EDNRB knockout mice show an aganglionic megacolon, a pigmentary disorder of the skin and can survive only up to 8 weeks. This may be due to failure of precursors of the enteric nervous system and neural crest-derived epidermal melanoblasts to colonize the intestines and skin. At the same time, EDN-3 knockout mice have an identical phenotype (14).

\section{CONCLUSION}

Taken together, there is a marked alteration in the expression of EDN system components in colorectal cancer and an obvious role of endothelin system members in all stages of colorectal cancer pathogenesis. There are promising results when using antagonists of the endothelin system in cancer treatment, both, in vivo and vitro. However, clinical trials in cancer patients based on a monotherapy with EDN receptor antagonists are not encouraging, and there is a growing trend to use these drugs as adjuvant therapeutics in combination with other conventional anticancer drugs. The roles of EDN-2 and EDN-3 in cancer will need more research.

\section{CONFLICT OF INTEREST}

The authors declare no conflict of interest.

\section{REFERENCES}

1. Nelson J, Bagnato A, Battistini B, Nisen P. The endothelin axis: emerging role in cancer. Nat Rev Cancer 2003;3:110-116. DOI: 10.1038/nrc990.

2. Khimji AK, Rockey DC. Endothelin - biology and disease. Cell Signal 2010;22:1615-1625. DOI: 10.1016/j. cellsig.2010.05.002.

3. Wang R, Lohr CV, Fischer K, Dashwood WM, Greenwood JA, Ho E, et al. Epigenetic inactivation of endothelin-2 and endothelin-3 in colon cancer. Int $J$ Cancer 2013;132:1004-1012. DOI: 10.1002/ijc.27762.
4. Barnes K, Turner AJ. The endothelin system and endothelin-converting enzyme in the brain: molecular and cellular studies. Neurochem Res 1997;22:1033-1040. DOI: 10.1023/A:1022435111928.

5. Bhalla A, Haque S, Taylor I, Winslet M, Loizidou M. Endothelin receptor antagonism and cancer. Eur J Clin Invest 2009;39 (Suppl 2):74-77. DOI: 10.1111/j.13652362.2009.02123.x.

6. Rosano L, Spinella F, Bagnato A. Endothelin 1 in cancer: biological implications and therapeutic opportunities. Nat Rev Cancer 2013;13:6376-6399. DOI: 10.1038/nrc3546.

7. McKenzie GAG, Hinsley EE, Hunter K, Lambert DW. The endothelin axis in head and neck cancer: a promising therapeutic opportunity? J Oral Pathol Med 2014;43:395404. DOI: $10.1111 /$ Jop. 12108.

8. Bremnes T, Paasche JD, Mehlum A, Sandberg C, Bremnes B, Attramadal H. Regulation and intracellular trafficking pathways of the endothelin receptors. J Biol Chem 2000;275:17596-17604. DOI: 10.1074/jbc.M000142200.

9. Abassi ZA, Tate JE, Golomb E, Keiser HR. Role of neutral endopeptidase in the metabolism of endothelin. Hypertension 1992;20:89-95. DOI: 10.1161/01. HYP.20.1.89.

10. Rubanyi GM, Polokoff MA. Endothelins: molecular biology, biochemistry, pharmacology, physiology, and pathophysiology. Pharmacol Rev 1994;46:325-415. PMID:7831383

11. Bagnato A, Loizidou M, Pflug BR, Curwen J, Growcott J. Role of the endothelin axis and its antagonists in the treatment of cancer. Br J Pharmacol 2011;163:220-233. DOI: 10.1111/j.1476-5381.2011.01217.x.

12. Arinami T, Ishikawa M, Inoue A, Yanagisawa M, Masaki $\mathrm{T}$, Yoshida MC, et al. Chromosomal assignments of the human endothelin family genes: the endothelin-1 gene (EDN1) to 6p23-p24, the endothelin-2 gene (EDN2) to 1p34, and the endothelin-3 gene (EDN3) to 20q13.2-q13.3. Am J Hum Gen 1991;48:990-996. PMID:2018043

13. Uchide T, Adur J, Fukamachi T, Saida K. Quantitative analysis of endothelin-1 and vasoactive intestinal contractor/endothelin-2 gene expression in rats by realtime reverse transcriptase polymerase chain reaction. J Cardiovasc Pharmacol 2000;36(5 Suppl 1):S5-8. DOI: 10.1097/00005344-200036001-00004.

14. Ling L, Maguire JJ, Davenport AP. Endothelin-2, the forgotten isoform: emerging role in the cardiovascular system, ovarian development, immunology and cancer. Br J Pharmacol 2013;168:283-295. DOI: 10.1111/j.1476-5381.2011.01786.x. 
15. Bianchi M, Adur J, Izaguirre MF, Viale S, Cesar CL, Casco VH. Endothelin-2 Differential Expression in Normal and Early-Stages of Colon Cancer Development. $J$ Cancer Ther 2013;4:26-33. DOI: 10.4236/jct.2013.46A2004.

16. Sakurai T, Yanagisawa M, Masaki T. Molecular characterization of endothelin receptors. Trends Pharmacol Sci 1992;13:103-108. DOI: http://dx.doi.org/10.1016/0165-6147(92)90038-8.

17. Hoosein MM, Dashwood MR, Dawas K, Ali HM, Grant K, Savage F, et al. Altered endothelin receptor subtypes in colorectal cancer. Eur J Gastroenterol Hepatol 2007;19:775-782 DOI: 10.1097/ MEG.0b013e3282c563de.

18. Hsu LS, Lee HC, Chau GY, Yin PH, Chi CW, Lui WY. Aberrant methylation of EDNRB and p16 genes in hepatocellular carcinoma (HCC) in Taiwan. Oncol Rep 2006;15:507-511. DOI: 10.3892/or.15.2.507.

19. Tao K, Wu C, Wu K, Li W, Han G, Shuai X, et al. Quantitative analysis of promoter methylation of the EDNRB gene in gastric cancer. Med Oncol 2012;29:107112. DOI: $10.1007 / \mathrm{s} 12032-010-9805-8$.

20. Dupuis J, Jasmin JF, Prie S, Cernacek P. Importance of local production of endothelin-1 and of the ET(B) Receptor in the regulation of pulmonary vascular tone. Pulm Pharmacol Ther 2000;13:135-140. DOI: 10.1006/ pupt.2000.0242.

21. Lahav R. Endothelin receptor B is required for the expansion of melanocyte precursors and malignant melanoma. Int J Dev Biol 2005;49:173-180. DOI: 10.1387/ijdb.041951rl.

22. Anguelova E, Beuvon F, Leonard N, Chaverot N, Varlet P, Couraud PO, et al. Functional endothelin ET B receptors are selectively expressed in human oligodendrogliomas. Brain Res Mol Brain Res 2005;137:77-88. DOI: 10.1016/j.molbrainres.2005.02.015.

23. Irani S, Salajegheh A, Smith RA, Lam AK. A review of the profile of endothelin axis in cancer and its management. Crit Rev Oncol Hematol 2014;89:314-321. DOI: 10.1016/j.critrevonc.2013.08.011.

24. Valdenaire O, Rohrbacher E, Mattei MG. Organization of the gene encoding the human endothelin-converting enzyme (ECE-1). J Biol Chem 1995;270:29794-29798. PMID:8530372.

http://www.jbc.org/content/270/50/29794

25. Emoto N, Yanagisawa M. Endothelin-converting enzyme-2 is a membrane-bound, phosphoramidonsensitive metalloprotease with acidic $\mathrm{pH}$ optimum. $J$ Biol Chem 1995;270:15262-15268. DOI: 10.1074/ jbc.270.25.15262.
26. Kawanabe Y, Nauli SM. Endothelin. Cell Mol Life Sci: CMLS 2011;68:195-203. DOI: 10.1007/s00018-0100518-0.

27. Lambert LA, Whyteside AR, Turner AJ, Usmani BA. Isoforms of endothelin-converting enzyme-1 (ECE-1) have opposing effects on prostate cancer cell invasion. Br J Cancer 2008;99:1114-1120. DOI: 10.1038/ sj.bjc. 6604631.

28. Haque SU, Dashwood MR, Heetun M, Shiwen X, Farooqui $\mathrm{N}$, Ramesh B, et al. Efficacy of the specific endothelin a receptor antagonist zibotentan (ZD4054) in colorectal cancer: a preclinical study. Mol Cancer Ther 2013;12:15561567. DOI: 10.1158/1535-7163.MCT-12-0975.

29. Simpson RA, Dickinson T, Porter KE, London NJ, Hemingway DM. Raised levels of plasma big endothelin 1 in patients with colorectal cancer. Br J Surg 2000;87:14091413. DOI: $10.1046 /$ j.1365-2168.2000.01536.x.

30. Shankar A, Loizidou M, Aliev G, Fredericks S, Holt D, Boulos PB, et al. Raised endothelin 1 levels in patients with colorectal liver metastases. Br J Surg 1998;85:502506. DOI: 10.1046/j.1365-2168.1998.00660.x.

31. Egidy G, Juillerat-Jeanneret L, Jeannin JF, Korth P, Bosman FT, Pinet F. Modulation of human colon tumorstromal interactions by the endothelin system. $A m J$ Pathol 2000;157:1863-1874. DOI: 10.1016/S00029440(10)64825-0.

32. Said N, Theodorescu D. Permissive role of endothelin receptors in tumor metastasis. Life Sci 2012;91:522-527. DOI: 10.1016/j.lfs.2012.03.040.

33. Asham E, Shankar A, Loizidou M, Fredericks S, Miller $\mathrm{K}$, Boulos PB, et al. Increased endothelin-1 in colorectal cancer and reduction of tumour growth by ET(A) receptor antagonism. Br J Cancer 2001;85:1759-1763. DOI: 10.1054/bjoc.2001.2193.

34. Liakou P, Tepetes K, Germenis A, Leventaki V, Atsaves $\mathrm{V}$, Patsouris E, et al. Expression patterns of endothelin-1 and its receptors in colorectal cancer. J Surg Oncol 2012;105:643-649. DOI: 10.1002/jso.23017.

35. Ali H, Dashwood M, Dawas K, Loizidou M, Savage F, Taylor I. Endothelin receptor expression in colorectal cancer. J Cardiovas Pharmacol 2000;36(5 Suppl 1):S6971. PMID:11078339

36. Fukui R, Nishimori H, Hata F, Yasoshima T, Ohno $\mathrm{K}$, Yanai $\mathrm{Y}$, et al. Inhibitory effect of endothelin A receptor blockade on tumor growth and liver metastasis of a human gastric cancer cell line. Gastric Cancer 2007; 10:123-128. DOI: 10.1007/s10120-0070421-z. 
37. Stow LR, Jacobs ME, Wingo CS, Cain BD. Endothelin-1 gene regulation. FASAB J 2011;25:16-28. DOI: 10.1096/ fj.10-161612.

38. Sorby LA, Kleiveland CR, Andersen SN, Bukholm IR, Jacobsen MB. The endothelin axis in the metastatic process of colon carcinoma. Anticancer Res 2011;31:861869, PMID:21498707

39. Truant SC, Gouyer VP, Leteurtre EA, Zerimech F, Huet GM, Pruvot FR. E-cadherin and beta-catenin mRNA levels throughout colon cancer progression. J Surg Res 2008;150:212-218 DOI: 10.1016/j.jss.2007.12.800.

40. Sun P, Xiong H, Kim TH, Ren B, Zhang Z. Positive interregulation between beta-catenin/T cell factor- 4 signaling and endothelin-1 signaling potentiates proliferation and survival of prostate cancer cells. Mol Pharmacol 2006;69:520-531. DOI: 10.1124/mol.105.019620.

41. Maniatis T. A ubiquitin ligase complex essential for the NF-kappaB, Wnt/Wingless, and Hedgehog signaling pathways. Genes Dev 1999;13:505-510. PMID:10072378

42. Cohen MM, Jr. Molecular dimensions of gastrointestinal tumors: some thoughts for digestion. Am J Med Genet Part A 2003;122A:303-314. DOI: 10.1002/ajmg.a.20473.

43. Bienz M, Clevers H. Linking colorectal cancer to Wnt signaling. Cell 2000; 103: 311-320. DOI: http://dx.doi.org/10.1016/S0092-8674(00)00122-7.

44. He X. A Wnt-Wnt situation. Dev Cell 2003;4:791-797. PMID: 12791265

45. Bagnato A, Cirilli A, Salani D, Simeone P, Muller A, Nicotra MR, et al. Growth inhibition of cervix carcinoma cells in vivo by endothelin A receptor blockade. Cancer Res 2002; 62: 6381-6384. http://cancerres.aacrjournals.org/content/62/22/6381

46. Rozengurt E. Mitogenic signaling pathways induced by G protein-coupled receptors. $J$ Cell Physiol 2007; 213: 589-602. DOI: 10.1002/jcp.21246.

47. Nelson JB, Udan MS, Guruli G, Pflug BR. Endothelin-1 inhibits apoptosis in prostate cancer. Neoplasia. 2005; 7 : 631-637. DOI: $10.1593 /$ neo.04787

48. Eberl LP, Egidy G, Pinet F, Juillerat-Jeanneret L. Endothelin receptor blockade potentiates FasL-induced apoptosis in colon carcinoma cells via the protein kinase C-pathway. J Cardiovasc Pharmacol 2000; 36 (Suppl 1):S354-356. DOI: 10.1097/00005344200036001-00103.

49. Kim TH, Xiong H, Zhang Z, Ren B. beta-Catenin activates the growth factor endothelin-1 in colon cancer cells. Oncogene. 2005;24(4):597-604 DOI: 10.1038/ sj.onc. 1208237.
50. Eberl LP, Valdenaire O, Saintgiorgio V, Jeannin JF, JuilleratJeanneret L. Endothelin receptor blockade potentiates FasL-induced apoptosis in rat colon carcinoma cells. Int $J$ Cancer 2000; 86: 182-187. DOI: 10.1002/(SICI)10970215(20000415)86:2<182::AID-IJC6>3.0.CO;2-G

51. Polyak K, Weinberg RA. Transitions between epithelial and mesenchymal states: acquisition of malignant and stem cell traits. Nature reviews Cancer. 2009;9(4):265-73 DOI: $10.1038 / \mathrm{nrc} 2620$.

52. Rosano L, Spinella F, Di Castro V, Nicotra MR, Dedhar S, de Herreros AG, et al. Endothelin-1 promotes epithelialto-mesenchymal transition in human ovarian cancer cells. Cancer research. 2005;65(24):11649-57 DOI: 10.1158/0008-5472.CAN-05-2123.

53. Maehama T, Dixon JE. PTEN: a tumour suppressor that functions as a phospholipid phosphatase. Trends Cell Biol 1999;9:125-128. DOI: http://dx.doi.org/10.1016/S0962-8924(99)01519-6.

54. Bowen KA, Doan HQ, Zhou BP, Wang Q, Zhou Y, Rychahou PG, et al. PTEN loss induces epithelial-mesenchymal transition in human colon cancer cells. Anticancer Res 2009;29:4439-4449. PMID:20032390

55. Bagnato A, Spinella F, Rosano L. The endothelin axis in cancer: the promise and the challenges of molecularly targeted therapy. Canad J Physiol Pharmacol 2008;86:473-484. DOI: 10.1139/Y08-058.

56. Knowles JP, Shi-Wen X, Haque SU, Bhalla A, Dashwood $\mathrm{MR}$, Yang S, et al. Endothelin-1 stimulates colon cancer adjacent fibroblasts. Int $J$ Cancer 2012;130:1264-1272. DOI: $10.1002 / \mathrm{ijc} .26090$.

57. Ziche M, Morbidelli L, Donnini S, Ledda F. ETB receptors promote proliferation and migration of endothelial cells. $J$ Cardiovasc Pharmacol 1995;26 (Suppl 3):S284-286. DOI: 10.1097/00005344-199506263-00085.

58. Huang WH, Chang MC, Tsai KS, Hung MC, Chen HL, Hung SC. Mesenchymal stem cells promote growth and angiogenesis of tumors in mice. Oncogene 2013;32:43434354. DOI: $10.1038 /$ onc.2012.458.

59. Puglisi MA, Barba M, Corbi M, Errico MF, Giorda E, Saulnier N, et al. Identification of Endothelin-1 and NR4A2 as CD133-regulated genes in colon cancer cells. J Pathol 2011;225:305-314. DOI: 10.1002/path.2954

60. Lloyd GM, Neal CP, Arun C, London NJ, Hemingway DM. The prognostic value of circulating big endothelin-1 in patients undergoing potentially curative resection for colorectal cancer. Colorect Dis 2011;13:290-295. DOI: 10.1111/j.1463-1318.2009.02129.x. 
61. Peeters CF, Thomas CM, Sweep FC, Span PN, Wobbes T, Ruers TM. Elevated serum endothelin-1 levels in patients with colorectal cancer; relevance for prognosis. Int J Biol Markers 2000;15:288-293. PMID:11192823

62. Kalles V, Zografos GC, Provatopoulou X, Kalogera E, Liakou P, Georgiou G, et al. Circulating levels of endothelin-1 (ET-1) and its precursor (Big ET-1) in breast cancer early diagnosis. Tum Biol 2012;33:1231-1236. DOI: $10.1007 / \mathrm{s} 13277-012-0371-\mathrm{x}$.

63. Pinto A, Merino M, Zamora P, Redondo A, Castelo B, Espinosa E. Targeting the endothelin axis in prostate carcinoma. Tum Biol 2012;33:421-426. DOI: 10.1007/ s13277-011-0299-6.

64. Ali H, Loizidou M, Dashwood M, Savage F, Sheard C, Taylor I. Stimulation of colorectal cancer cell line growth by ET-1 and its inhibition by ET(A) antagonists. Gut 2000;47:685-688. DOI: 10.1136/gut.47.5.685.

65. Grant K, Knowles J, Dawas K, Burnstock G, Taylor I, Loizidou M. Mechanisms of endothelin 1-stimulated proliferation in colorectal cancer cell lines. Br J Surg 2007;94:106-112. DOI: 10.1002/bjs.5536.

66. Eberl LP, Bovey R, Juillerat-Jeanneret L. Endothelinreceptor antagonists are proapoptotic and antiproliferative in human colon cancer cells. Br J Cancer 2003;88:788795. DOI: DOI 10.1038/sj.bjc.6600810.

67. Nie S, Zhou J, Bai F, Jiang B, Chen J, Zhou J. Role of endothelin A receptor in colon cancer metastasis: in vitro and in vivo evidence. Mol Carcinogen 2014;53 (Suppl 1):E85-91. DOI: 10.1002/mc.22036.

68. Carducci MA, Nelson JB, Bowling MK, Rogers T, Eisenberger MA, Sinibaldi V, et al. Atrasentan, an endothelin-receptor antagonist for refractory adenocarcinomas: safety and pharmacokinetics. $J$ Clin Oncol 2002;20:2171-2180. DOI: 10.1200/ JCO.2002.08.028.

69. Ferrero E, Labalde M, Fernandez N, Monge L, Salcedo A, Narvaez-Sanchez R, et al. Response to endothelin-1 in arteries from human colorectal tumours: role of endothelin receptors. Exp Biol Med 2008;233:1602-1607. DOI: 10.3181/0802-RM-69.

70. Chen C, Wang LY, Liao Q, Huang Y, Ye HD, Chen F, et al. Hypermethylation of EDNRB promoter contributes to the risk of colorectal cancer. Diagn Pathol 2013;8:199 DOI: Artn 199 Doi 10.1186/1746-1596-8-199.

71. Haque SU, Morton D, Welch H. Biologics against cancer-specific receptors - challenges to personalised medicine from early trial results. Curr Opin Pharmacol 2012;12:392-397. DOI: 10.1016/j.coph.2012.05.003.

72. Kedzierski RM, Yanagisawa M. Endothelin system: the double-edged sword in health and disease. Annu Rev Pharmacol Toxicol 2001;41:851-876. DOI: 10.1146/ annurev.pharmtox.41.1.851. 